\title{
Synthesis, Crystal Structure, and Transport Properties of $\mathrm{Na}_{22} \mathrm{Si}_{136}$
}

\author{
M. BEEKMAN, ${ }^{1}$ C.P. SEBASTIAN ${ }^{2}$ YU. GRIN ${ }^{2}$ and G.S. NOLAS ${ }^{1,3}$ \\ 1.-Department of Physics, University of South Florida, Tampa, FL 33620, USA. 2.-Max-Planck- \\ Institut für Chemische Physik fester Stoffe, Nöthnitzer Straße 40, 01187 Dresden, Germany. \\ 3.-e-mail: gnolas@cas.usf.edu
}

The type II clathrate $\mathrm{Na}_{22} \mathrm{Si}_{136}$ is prepared by the thermal decomposition of $\mathrm{NaSi}$. Thermal analysis indicates this phase is metastable yet has a relatively high decomposition temperature. Rietveld analysis indicates that $\mathrm{Na}$ in the larger $\mathrm{Si}_{28}$ cage is shifted off-center, analogous to observations in some type I clathrates. Temperature-dependent electrical and thermal transport properties are reported for $\mathrm{Na}_{22} \mathrm{Si}_{136}$, for which the spark plasma sintering technique was found to be effective in achieving intergrain sintering in the consolidated specimen. The potential that type II clathrate materials possess for thermoelectric applications is discussed.

Key words: Thermoelectric, clathrate, sodium, silicon, crystal structure, transport properties

\section{INTRODUCTION}

Since the identification of intermetallic clathrates based on elements of group $14(\mathrm{Si}, \mathrm{Ge}$, and $\mathrm{Sn})$ as prospective thermoelectric materials, ${ }^{1,2}$ significant effort has been exerted in order to understand the physical and chemical properties of these intriguing materials. ${ }^{3-6}$ Characterized by an open-structured, covalently bonded framework that can host various guest species in large, cage-like voids, intermetallic clathrates have been shown ${ }^{2,3,7}$ to exemplify the phonon glass electron crystal $^{8}$ concept. The endeavor to optimize these materials for potential high-temperature thermoelectric power generation applications continues, with recent promising reported successes. ${ }^{5,9-13}$

To date, research effort on clathrate compounds has predominantly focused on those with the type I crystal structure. ${ }^{3-5}$ Clathrates of the type II structure have recently attracted increasing attention. ${ }^{6}$ The type II clathrate (space group $F d \overline{3} m$ ) crystal structure is comprised of a covalently bonded framework $\left(\mathrm{E}_{136}\right.$ in the conventional cell, $\mathrm{E}=\mathrm{Si}, \mathrm{Ge}$, or $\mathrm{Sn}$ ) formed by the face sharing of 20 -membered

(Received July 29, 2008; accepted December 17, 2008;

published online January 19, 2009) dodecahedra $\left(\mathrm{E}_{20}\right)$ and 28-membered hexakaidecahedra $\left(\mathrm{E}_{28}\right)$ in an $\mathrm{E}_{28}: \mathrm{E}_{20}$ ratio of 1:2. The framework may be empty, as in the case of $\mathrm{E}=\mathrm{Si}^{14,15}$ or $\mathrm{Ge},{ }^{16}$ or its polyhedral cages can incorporate guest atomic species in their interiors. Large-amplitude, localized vibrations of these guests in the relatively oversized framework cages can potentially result in strong scattering of the heat-carrying phonons. $^{3-7,17-19}$ This aspect, coupled with the favorable electrical properties that semiconducting type II clathrates are expected to possess, forms the impetus for investigation of these materials for potential thermoelectric applications.

In addition to the rich possibilities for investigation of new compositions of thermoelectric clathrates, type II clathrate materials exhibit the characteristic that the guest content may be continuously varied, which may have conspicuous consequences for the physical properties of these materials. In particular, as the electronic and thermal properties of intermetallic clathrates are intimately related to the interaction between the guest and framework, this could offer tunability with respect to thermoelectric properties. The prototypical type II clathrate phases for which the guest content may be varied completely from unfilled $(x=0)$ to fully filled $(x=24)$ are the $\mathrm{Na}_{x} \mathrm{Si}_{136}$ 
$(0<x<24)$ clathrates. ${ }^{20-22}$ These phases have received considerable attention with respect to understanding some of their physical properties. ${ }^{6}$ However, presumably due to challenges inherent in the preparation of specimens for such study, their transport and thermoelectric properties remain to be well characterized. Herein, we report on the synthesis, structural, and transport properties of the $\mathrm{Na}_{22} \mathrm{Si}_{136}$ clathrate.

\section{EXPERIMENTAL}

The $\mathrm{Na}_{22} \mathrm{Si}_{136}$ specimen was prepared via thermal decomposition under vacuum $\left(10^{-5}\right.$ Torr $)$ of the Zintl phase $\mathrm{NaSi}^{20-22}$ by heating at $380^{\circ} \mathrm{C}$ for $1.5 \mathrm{~h}$. $\mathrm{NaSi}$ was first prepared from elemental $\mathrm{Na}(99.95 \%)$ and $\mathrm{Si}(99.999 \%)$ by reaction in tungsten crucibles at $650^{\circ} \mathrm{C}$ for $36 \mathrm{~h}$, sealed under nitrogen in a steel reaction vessel. All manipulations were performed inside nitrogen- or argon-filled glove boxes. The products of thermal decomposition of $\mathrm{NaSi}$ were fine polycrystalline powders. The thermal decomposition of $\mathrm{NaSi}$ to form $\mathrm{Na}_{x} \mathrm{Si}_{136}$ is complicated by the presence of the type I clathrate $\mathrm{Na}_{8} \mathrm{Si}_{46}$ which also readily forms in this process, the content of which can vary from several wt.\% to almost $50 \mathrm{wt} . \%$ in assynthesized specimens. ${ }^{21,22}$ In the $\mathrm{Na}_{22} \mathrm{Si}_{136}$ specimen as synthesized in the present study, the $\mathrm{Na}_{8} \mathrm{Si}_{46}$ phase fraction was less than 3 vol.\% (as estimated from Rietveld refinement), without the need for further density separation and purification as previously reported. ${ }^{22}$

Powder x-ray diffraction (XRD) data were collected at room temperature in the $2 \theta$ range of $7 \mathrm{deg}$ to $145 \mathrm{deg}$, utilizing $\mathrm{Cu} \mathrm{K} \alpha$ radiation. Rietveld structure refinements were carried out using the GSAS software suite ${ }^{23,24}$ and WinCSD software package. ${ }^{25}$ Differential thermal analysis (DTA), conducted using a TA Instruments SDT Q600, showed no thermal events until just below $600^{\circ} \mathrm{C}$, whereupon a weak exothermic peak was observed, indicating that the $\mathrm{Na}_{22} \mathrm{Si}_{136}$ phase is metastable. Post-DTA XRD revealed the post-decomposition (of $\mathrm{Na}_{22} \mathrm{Si}_{136}$ ) product to be diamond silicon, in agreement with a theoretical study ${ }^{26}$ that concludes that the empty $\mathrm{Si}_{136}$ clathrate is only slightly higher in energy than the diamond-structured Si ground state.

The $\mathrm{Na}_{22} \mathrm{Si}_{136}$ specimen prepared for transport property measurements was consolidated under argon at $450^{\circ} \mathrm{C}$ using a custom-designed ${ }^{27}$ spark plasma sintering (SPS) apparatus contained inside an argon-filled glove box. The resulting pellet density was approximately $83 \%$ of the calculated value from the XRD data. A parallelepiped specimen of approximate dimensions $2 \mathrm{~mm} \times 2 \mathrm{~mm} \times 5 \mathrm{~mm}$ for temperature-dependent transport measurements was cut from the resulting pellet using a wire saw. Electrical resistivity $(\rho)$ was measured using a four-probe method. The Seebeck coefficient $(S)$ at each temperature was measured from the slope of a $\Delta V$ versus $\Delta T$ plot acquired by a temperature gradient sweep method. Thermal conductivity $(\kappa)$ was measured by a standard steady-state heat flow technique.

\section{RESULTS AND DISCUSSION}

The initial model used for Rietveld refinement (Fig. 1a) was taken by assuming the framework $\mathrm{Si}$ atoms at the $96 \mathrm{~g}, 32 e$, and $8 a$ sites, and the $\mathrm{Na}$ atoms at the centers of the $\mathrm{Si}_{20}$ and $\mathrm{Si}_{28}$ cages at the $16 c$ and $8 b$ sites, respectively. ${ }^{20-22}$ However, the isotropic atomic displacement parameters* $\left(U_{\text {iso }}\right)$ for $\mathrm{Na}$ at the $8 b$ site (fractional coordinates: $3 / 8,3 / 8$, $3 / 8)$ was found to be unreasonably large $\left(>0.1 \AA^{2}\right.$, several times larger than any other site in the structure; see Table I). Although strong thermal motion is expected for this caged guest, especially considering the relatively large difference between the size of the Na guest and the effective free space of the cage interior, the unusually large $U_{\text {iso }}$ suggests, in addition, that significant static disorder may be present. Difference Fourier maps, computed using the calculated structure factors for the model with $\mathrm{Na}$ at the $8 b$ site completely unoccupied, indicate significantly nonspherical residual electron density in the vicinity of the $8 b$ site, and typically with lobes directed toward the hexagonal faces of the $\mathrm{Si}_{28}$ cage. For specimens with lower Na content, the maxima in density are observed not on-center at the $8 b$ site, but rather at four nearby sites within the $\mathrm{Si}_{28}$ cage $(3 / 8+\delta, 3 / 8+\delta, 3 / 8+\delta)$. Therefore, further refinement was carried out using a split-site model with $\mathrm{Na}$ at the corresponding nearby $32 e$ site (still with space group $F d \overline{3} m$ ). Figure $1 \mathrm{~b}$ shows the calculated and measured diffraction profile for the $\mathrm{Na}_{22} \mathrm{Si}_{136}$ specimen (refined composition $\mathrm{Na}_{21.7} \mathrm{Si}_{136}$ ), while refinement results and refined structural parameters are given in the table.

Stable refinement convergence, with no damping of parameter shifts, was achieved with final simultaneous refinement of $\mathrm{Na}$ occupancy, $U_{\mathrm{iso}}$, and $32 e$ positional parameter for this site. The refined offcenter shift for the sodium atom was found to be approximately $0.4 \AA$. Moreover, the occupancy for the $\mathrm{Na}$ at $32 e$ split-site model refined to be onequarter of the corresponding single site (i.e., $\mathrm{Na}$ at $8 b$ model) occupancy, consistent with the fourfold increase in site multiplicity from $8 a$ to $32 e$, and the physical requirement of only one $\mathrm{Na}$ atom per cage. These results indicate that $\mathrm{Na}$ is indeed shifted significantly off-center in the $\mathrm{Si}_{28}$ cage. Our conclusion confirms findings from recent extended $\mathrm{x}$-ray absorption fine-structure (EXAFS) studies, which indicate significant displacement of $\mathrm{Na}$ from the center of the hexakaidecahedra in $\mathrm{Na}_{8} \mathrm{Si}_{136}$ and $\mathrm{Na}_{24} \mathrm{Si}_{136}{ }^{28,29}$ The value $\sim 0.4 \AA$ for the $\mathrm{Na}$ shift in $\mathrm{Na}_{22} \mathrm{Si}_{136}$ is similar to that observed for guests in

\footnotetext{
*The $96 g$ site is the only site for which the diagonal elements of the anisotropic atomic displacement parameter tensor $U_{i j}$ $(i=j=1,2,3)$ are unequal.
} 

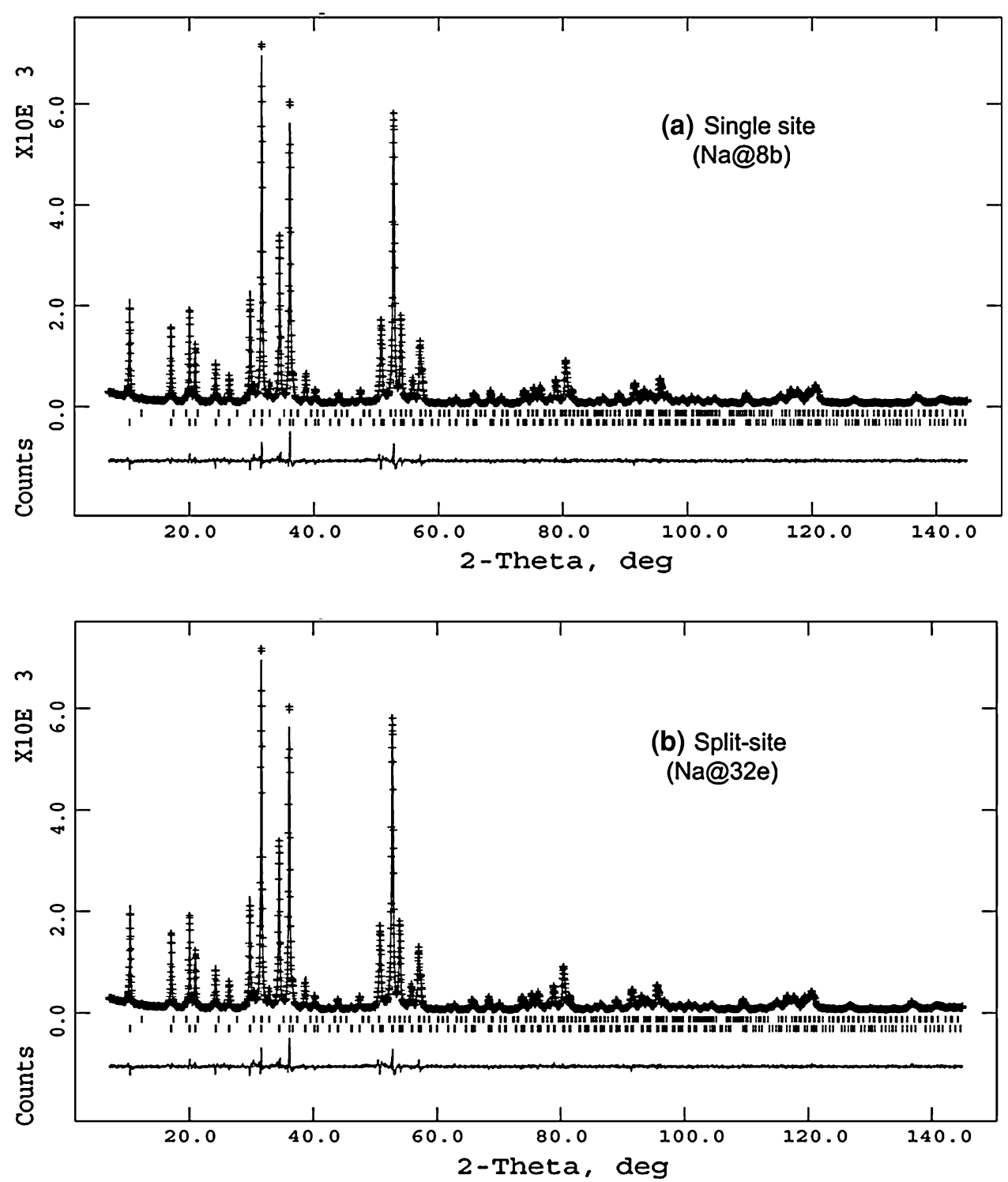

Fig. 1. Rietveld refinement powder pattern plots for $\mathrm{Na}_{22} \mathrm{Si}_{136}$, using the single-site (a) and split-site (b) models discussed in the text. Lower tick marks indicate $\mathrm{Na}_{x} \mathrm{Si}_{136}$ reflection positions, whereas upper tick marks indicate reflections due to the type I $\mathrm{Na}_{8} \mathrm{Si}_{46}$ clathrate impurity phase (phase fraction estimated to be less than 3 vol. \%).

the $\mathrm{Ge}_{24}$ tetrakaidecahedra cage in type I clathrates such as $\mathrm{Sr}_{8} \mathrm{Ga}_{16} \mathrm{Ge}_{30}$ and $\mathrm{Eu}_{8} \mathrm{Ge}_{16} \mathrm{Ge}_{30} .{ }^{30,31}$

The refined $\mathrm{Na}$ at $32 e U_{\text {iso }}$ value is reduced to more physically reasonable values for the split-site model (Table I), yet still remains relatively large. As mentioned above, this is consistent with strong thermal disorder for $\mathrm{Na}$ in the larger cage; further study is in progress, as this may have important implications regarding the thermal conduction in these materials. We note that in our refinements strong correlations exist between the $\mathrm{Na} U_{\text {iso }}$ and $32 e$ position parameter, thus it is difficult to obtain precise values for the position and $U_{\text {iso }}$ from our data. As the refinement quality of fit (Fig. 1 and Table I) are the same for the on-center and offcenter models, preference for one model over the other cannot be based on these factors alone.
However, smaller residual electron density in the case of the split-site model and the physically more reasonable $U_{\text {iso }}$ are obtained in the off-center model. Similar results and conclusions were obtained in structural studies of type I clathrates, ${ }^{30,32-34}$ for which single- and split-site models both result in similar refinement quality. The off-centering of the guest atoms in type I clathrates results in unique phenomena in these compounds. ${ }^{7,35,36}$ Further detailed analysis for a series of $\mathrm{Na}_{x} \mathrm{Si}_{136}(0<x<24)$ will be reported elsewhere.

One of the challenges inherent to a study of the transport properties of the $\mathrm{Na}_{x} \mathrm{Si}_{136}$ clathrates is preparation of sufficiently dense polycrystalline samples with good intergrain electrical contact. Analogous to silicon in the diamond structure, an insulating oxide layer can readily form on the grains 
Table I. Crystallographic Data for $\mathrm{Na}_{22} \mathrm{Si}_{136}$ (Space Group $\mathrm{Fd} \overline{\mathbf{3}} m$ )

\begin{tabular}{|c|c|c|c|c|c|c|c|}
\hline Atom & Site & Symmetry & $x$ & $y$ & $z$ & Occupancy & $U_{\text {eq }}\left(\AA^{\mathbf{2}}\right)$ \\
\hline \multicolumn{8}{|c|}{ Single-site model $(\mathrm{Na} \text { at } 8 b)^{\mathrm{a}}$} \\
\hline \multicolumn{8}{|c|}{ Refined composition $\mathrm{Na}_{21.6} \mathrm{Si}_{136} ; a=14.7103(2) \AA$} \\
\hline $\mathrm{Na} 1$ & $16 c$ & $3 m$ & 0 & 0 & 0 & $0.853(4)$ & $0.0141(9)$ \\
\hline $\mathrm{Na} 2$ & $8 b$ & $\overline{4} 3 m$ & $3 / 8$ & $3 / 8$ & $3 / 8$ & 1 & $0.118(2)$ \\
\hline Si1 & $96 g$ & $m$ & $0.06715(3)$ & $x$ & $0.37156(6)$ & 1 & $0.0072^{\mathrm{b}, \mathrm{c}}$ \\
\hline $\mathrm{Si} 2$ & $32 e$ & $3 m$ & $0.21833(5)$ & $x$ & $x$ & 1 & $0.0071(4)$ \\
\hline $\mathrm{Si} 3$ & $8 a$ & $\overline{4} 3 m$ & $1 / 8$ & $1 / 8$ & $1 / 8$ & 1 & $0.0051(6)$ \\
\hline \multicolumn{8}{|c|}{ Split-site model $(\mathrm{Na} \text { at } 32 e)^{\mathrm{d}}$} \\
\hline \multicolumn{8}{|c|}{ Refined composition: $\mathrm{Na}_{21.7} \mathrm{Si}_{136} \cdot a=14.7104(2) \AA$} \\
\hline $\mathrm{Na} 1$ & $16 c$ & $3 m$ & 0 & 0 & 0 & $0.854(4)$ & $0.0145(9)$ \\
\hline Na2 & $32 e$ & $3 m$ & $0.3909(9)$ & $x$ & $x$ & $0.251(2)$ & $0.061(8)$ \\
\hline Si1 & $96 g$ & $m$ & $0.06716(3)$ & $x$ & $0.37155(6)$ & 1 & $0.0072^{\mathrm{b}, \mathrm{e}}$ \\
\hline $\mathrm{Si} 2$ & $32 e$ & $3 m$ & $0.21832(5)$ & $x$ & $x$ & 1 & $0.0072(4)$ \\
\hline $\mathrm{Si} 3$ & $8 a$ & $\overline{4} 3 m$ & $1 / 8$ & $1 / 8$ & $1 / 8$ & 1 & $0.0051(6)$ \\
\hline
\end{tabular}

${ }^{\mathrm{a}}$ Residuals: $\chi^{2}=1.65, R_{w p}=0.085, R_{p}=0.064, R\left(F^{2}\right)=0.024$; ${ }^{\mathrm{b}}$ See footnote $1 ;{ }^{\mathrm{c}} U_{11}=U_{22}=0.0051(3), U_{33}=0.0115(6), U_{12}=0.0021(4)$, $U_{13}=U_{23}=0.0005(3) ; \quad{ }^{\mathrm{d}}$ Residuals: $\chi^{2}=1.65, \quad R_{w p}=0.085, \quad R_{p}=0.064, \quad R\left(F^{2}\right)=0.024 ; \quad{ }^{\mathrm{e}} U_{11}=U_{22}=0.0049(3), \quad U_{33}=0.0127(6)$, $U_{12}=0.0023(4), U_{13}=U_{23}=0.0003(3)$.

of the polycrystalline specimens. This oxide layer has been directly observed in the $\mathrm{Na}_{x} \mathrm{Si}_{136}$ clathrates, ${ }^{37}$ and can present difficulties in both densification $^{38}$ and interpretation of the measured transport properties. ${ }^{39}$ The SPS technique has been shown to be very effective in the preparation and consolidation of a diverse range of materials. ${ }^{40-42}$

The measured $\rho, S$, and $\kappa$ in the temperature range of $60 \mathrm{~K}$ to $300 \mathrm{~K}$ for the $\mathrm{Na}_{22} \mathrm{Si}_{136}$ specimen consolidated using SPS are shown in Fig. 2. $\rho$ increases monotonically with temperature, and remains less than $1 \mathrm{mOhm} \mathrm{cm}$ in the entire temperature range. The value of $0.7 \mathrm{mOhm} \mathrm{cm}$ at $300 \mathrm{~K}$ is very close to that reported ${ }^{17}$ for the stoichiometric clathrate $\mathrm{Cs}_{8} \mathrm{Na}_{16} \mathrm{Si}_{136}$. The values for $S$ remain relatively low, and the magnitude also increases monotonically with temperature. The negative sign of $S$ suggests that electrons are the majority carriers. The observed magnitude and temperature dependence of both $\rho$ and $S$ for $\mathrm{Na}_{22} \mathrm{Si}_{136}$ are indicative of metallic or very heavily doped semiconductor behavior.

A metal-insulator transition has been reported ${ }^{39,43}$ to occur in $\mathrm{Na}_{x} \mathrm{Si}_{136}$ near $7<x<11$, though the precise value of $x$ at which this occurs, as well as the nature of this transition, has yet to be determined unequivocally. For the high Na content of $\mathrm{Na}_{22} \mathrm{Si}_{136}$, the electronic properties can be qualitatively understood in terms of a simplified rigid-band model, wherein electronic charge is transferred from the $\mathrm{Na}$ guests to the framework, therefore resulting in the occupation of the framework conduction bands, and the observed metallic properties. This qualitatively explains the observed behavior in Fig. 2. Our transport measurements confirm that intergrain sintering and relatively good electrical contact between the grains is achieved using the SPS method.
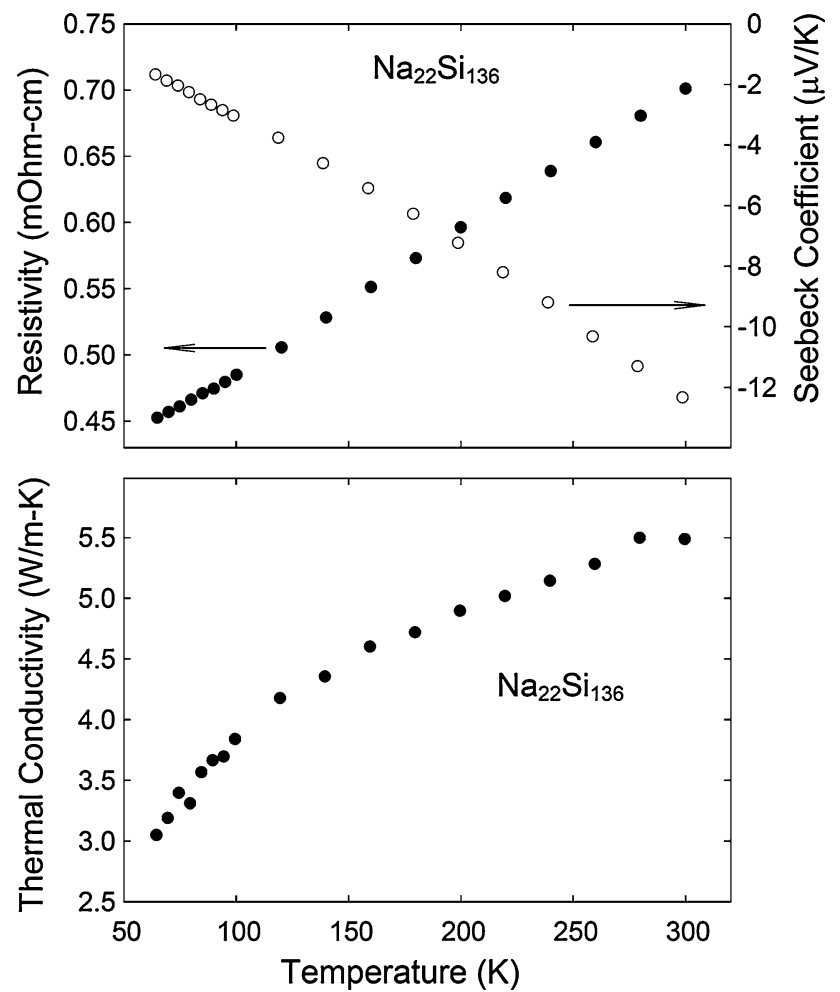

Fig. 2. Electrical resistivity and Seebeck coefficient (top), and thermal conductivity (bottom) for the $\mathrm{Na}_{22} \mathrm{Si}_{136}$ specimen consolidated using the SPS technique.

The total measured thermal conductivity $(\kappa)$ for the $\mathrm{Na}_{22} \mathrm{Si}_{136}$ specimen is shown in Fig. 2 (bottom). These data have not been corrected for the $\sim 17 \%$ porosity in this specimen, which may have a nonnegligible effect on the perceived $\kappa$. The temperature dependence of $\kappa$ is similar to that reported for $\mathrm{Cs}_{8} \mathrm{Na}_{16} \mathrm{Si}_{136}{ }^{17}$ and also the type I $\mathrm{Na}_{8} \mathrm{Si}_{46}{ }^{44}$ 
$\kappa$ achieves a modest value of $\sim 5.5 \mathrm{~W} / \mathrm{m} / \mathrm{K}$ at $300 \mathrm{~K}$. Our previous investigation into the thermal conductivity of hot-pressed $\mathrm{Na}_{x} \mathrm{Si}_{136}(x=0,1$, and 8) clathrates suggests that the semiconducting variants possess relatively low thermal conductivities. ${ }^{45,46}$ Results from a complete study of the transport properties of $\mathrm{Na}_{x} \mathrm{Si}_{136}(0<x<24)$ will be reported elsewhere.

\section{CONCLUSION}

The type II clathrate $\mathrm{Na}_{22} \mathrm{Si}_{136}$ was prepared by the thermal decomposition of $\mathrm{NaSi}$ in vacuum. Structural analysis reveals that the Na guest in the larger $\mathrm{Si}_{28}$ cage is shifted off-center by at least $0.4 \AA$, which may have important consequences for the physical properties of these materials. In particular, electronic structure calculations for $\mathrm{Na}_{x} \mathrm{Si}_{136}$ clathrates should be revisited in light of this observation. We have reported for the first time all three thermoelectric transport coefficients for a $\mathrm{Na}_{x} \mathrm{Si}_{136}$ specimen with $x=22$ : temperaturedependent electrical resistivity, Seebeck coefficient, and thermal conductivity. SPS consolidation was found to be effective in achieving good intergrain sintering and electrical contact.

\section{ACKNOWLEDGEMENTS}

M.B. and G.S.N. acknowledge support from the US Department of Energy under Grant No. DE-FG02-04ER46145. M.B. acknowledges support from the University of South Florida Presidential Doctoral Fellowship. M.B. also acknowledges useful discussions with Jan Gryko concerning the synthesis of $\mathrm{Na}_{x} \mathrm{Si}_{136}$ clathrates.

\section{REFERENCES}

1. G.A. Slack, Mater. Res. Soc. Symp. Proc. 478, 47 (1997).

2. G.S. Nolas, J.L. Cohn, G.A. Slack, and S.B. Schujman, Appl. Phys. Lett. 73, 178 (1998). doi:10.1063/1.121747.

3. G.S. Nolas, G.A. Slack, and S.B. Schujman, Semiconductors and Semimetals, Vol. 69, ed. T.M. Tritt (San Diego: Academic), p. 255.

4. G.S. Nolas, Chemistry, Physics, and Materials Science of Thermoelectric Material: Beyond Bismuth Telluride, ed. M.G. Kanatzidis, S.D. Manhanti, and T.P. Hogan (New York: Kluwer Academic, 2003), pp. 107-120.

5. G.S. Nolas, Thermoelectrics Handbook: Macro to Nano, ed. D.M. Rowe (Boca Raton: CRC, 2006), pp. 33-41.

6. M. Beekman and G.S. Nolas, J. Mater. Chem. 18, 842 (2008). doi:10.1039/b706808e.

7. J.L. Cohn, G.S. Nolas, V. Fessatidis, T.H. Metcalf, and G.S. Slack, Phys. Rev. Lett. 82, 779 (1999). doi:10.1103/PhysRevLett.82.779.

8. G.A. Slack, CRC Handbook of Thermoelectrics, ed. D.M. Rowe (Boca Raton, FL: CRC, 1994), p. 407.

9. A. Saramat, G. Svensson, A.E.C. Palmqvist, C. Stiewe, E. Mueller, D. Platzek, S.G.K. Williams, D.M. Rowe, J.D. Bryan, and G.D. Stucky, J. Appl. Phys. 99, 23708 (2006). doi:10.1063/1.2163979.

10. J.-H. Kim, N.L. Okamoto, K. Kishida, K. Tanaka, and H. Inui, Acta Mater. 54, 2057 (2006). doi:10.1016/j.actamat.2005. 12.032 .

11. J. Martin, G.S. Nolas, H. Wang, and J. Yang, J. Appl. Phys. 102, 103719 (2007). doi:10.1063/1.2817400.
12. J. Martin, H. Wang, and G.S. Nolas, Appl. Phys. Lett. 92, 222110 (2008). doi:10.1063/1.2939438.

13. E.S. Toberer, M. Christensen, B.B. Iversen, and G.J. Snyder, Phys. Rev. B 77, 075203 (2008). doi:10.1103/PhysRevB.77. 075203.

14. J. Gryko, P.F. McMillan, R.F. Marzke, G.K. Ramachandran, D. Patton, S.K. Deb, and O.F. Sankey, Phys. Rev. B 62, R7707 (2000). doi:10.1103/PhysRevB.62.R7707.

15. A. Ammar, C. Cros, M. Pouchard, N. Jaussaud, J.-M. Bassat, G. Villeneuve, M. Duttine, M. Ménétrier, and E. Reny, Solid State Sci. 6, 393 (2004). doi:10.1016/j.solidstatesciences.2004.02.006.

16. A.M. Guloy, R. Ramlau, Z. Tang, W. Schnelle, M. Baitinger, and Yu. Grin, Nature 443, 320 (2006). doi:10.1038/nature05145.

17. G.S. Nolas, D.G. Vanderveer, A.P. Wilkinson, and J.L. Cohn, J. Appl. Phys. 91, 8970 (2002). doi:10.1063/1.1471370.

18. G.S. Nolas, C.A. Kendziora, J. Gryko, J.J. Dong, C.W. Myles, A. Poddar, and O.F. Sankey, J. Appl. Phys. 92, 7225 (2002). doi:10.1063/1.1523146.

19. C.W. Myles, J.J. Dong, and O.F. Sankey, Phys. Stat. Solid. 239, 26 (2003). doi:10.1002/pssb.200303236.

20. C. Cros, M. Pouchard, and P. Hagenmuller, J. Solid State Chem. 2, 570 (1970). doi:10.1016/0022-4596(70)90053-8.

21. G.K. Ramachandran, J.J. Dong, J. Diefenbacher, J. Gryko, R.F. Marzke, O.F. Sankey, and P.F. McMillan, J. Solid State Chem. 145, 716 (1999). doi:10.1006/jssc.1999.8295.

22. E. Reny, P. Gravereau, C. Cros, and M. Pouchard, J. Mater. Chem. 8, 2839 (1998). doi:10.1039/a804565h.

23. A.C. Larson and R.B. Von Dreele, General Structure Analysis System (GSAS). Los Alamos National Laboratory Report LAUR 86-748 (2004).

24. B.H. Toby, J. Appl. Cryst. 34, 210 (2001). doi:10.1107/ S0021889801002242.

25. L.G. Akselrud, P.Y. Zavalii, Y.N. Grin, V.K. Pecharski, B. Baumgartner, and E. Wölfel, Mater. Sci. Forum 133-136, 335 (1993).

26. G.B. Adams, M. O'Keeffe, A.A. Demkov, O.F. Sankey, and Y.-M. Huang, Phys. Rev. B 49, 8048 (1994). doi:10.1103/ PhysRevB.49.8048.

27. N. Reinfried, P. Höhn, and Yu. Grin, Scientific Report (Germany: Max-Planck-Institut für Chemische Physik fester Stoffe, 2006), pp. 28-31.

28. F. Brunet, P. Mélinon, A. San-Miguel, P. Kéghélian, A. Perez, A.M. Flank, E. Roney, C. Cros, and M. Pouchard, Phys. Rev. B 61, 16550 (2000). doi:10.1103/PhysRevB.61.16550.

29. F. Tournus, B. Masenelli, P. Mélinon, D. Connétable, X. Blase, A.M. Flank, P. Lagarde, C. Cros, and M. Pouchard, Phys. Rev. B 69, 035208 (2004), doi:10.1103/PhysRevB.69.035208.

30. B.C. Chakoumakos, B.C. Sales, D.G. Mandrus, and G.S Nolas, J. Alloys Compd. 296, 80 (2000).

31. R. Baumbach, F. Bridges, L. Downward, D. Cao, P. Chesler, and B. Sales, Phys. Rev. B 71, 024202 (2005). doi:10.1103/ PhysRevB.71.024202.

32. M. Christensen, N. Lock, J. Overgarrd, and B.B. Iversen, J. Am. Chem. Soc. 128, 15657 (2006). doi:10.1021/ja063695y.

33. W. Carrillo-Cabrera, S. Budnyk, Y. Prots, and Y. Grin, $Z$. Anorg. Allg. Chem. 630, 2267 (2004). doi:10.1002/zaac. 200400268.

34. W. Carrillo-Cabrera, R. Cardoso Gil, S. Paschen, and Yu. Grin, Z. Kristallogr. NCS 217, 183 (2002).

35. R.P. Hermann, V. Keppens, P. Bonville, G.S. Nolas, F. Grandjean, G.J. Long, H.M. Christen, B.C. Chakoumakos, B.C. Sales, and D. Mandrus, Phys. Rev. Lett. 97, 17401 (2006). doi:10.1103/PhysRevLett.97.017401.

36. F. Bridges and L. Downward, Phys. Rev. B 70, 140201(R) (2004).

37. J. He, D.D. Klug, K. Uehara, K.F. Preston, C.I. Ratcliffe, and J.S. Tse, J. Phys. Chem. 105, 3475 (2001). doi:10.1021/ jp010255e.

38. C.J. Santana and K.S. Jones, J. Mater. Sci. 31, 4985 (1996). doi:10.1007/BF00355891.

39. N.F. Mott, J. Solid State Chem. 6, 348 (1973). doi:10.1016/ 0022-4596(73)90221-1. 
40. A. Leithe-Jasper, W. Schnelle, H. Rosner, N. Senthikumaran, A. Rabis, M. Baenitz, A. Gippius, E. Morozova, J.A. Mydosh, and Yu. Grin, Phys. Rev. Lett. 91, 037208 (2003). doi:10.1103/ PhysRevLett.91.037208.

41. Z.A. Munir, U. Anselmi-Tamburini, and M. Ohyanagi, J. Mater. Sci. 41, 763 (2006). doi:10.1007/s10853-006-6555-2.

42. C. Recknagel, N. Reinfried, P. Höhn, W. Schnelle, H. Rosner, Yu. Grin, and A. Leithe-Jasper, Sci. Technol. Adv. Mater. 8, 357 (2007). doi:10.1016/j.stam.2007.06.007.
43. S.B. Roy, K.E. Sim, and A.D. Caplan, Philos. Mag. B 65, 1445 (1992). doi:10.1080/13642819208215112.

44. G.S. Nolas, J.-M. Ward, J. Gryko, L. Qui, and M.A. White, Phys. Rev. B 64, 153201 (2001). doi:10.1103/PhysRevB.64.153201.

45. G.S. Nolas, M. Beekman, J. Gryko, G.A. Lamberton Jr., T.M. Tritt, and P.F. McMillan, Appl. Phys. Lett. 82, 910 (2003). doi:10.1063/1.1544640.

46. M. Beekman and G.S. Nolas, Physica B 383, 111 (2006). doi:10.1016/j.physb.2006.03.070. 